International Journal of Social Sciences and Humanities
Available online at http://sciencescholar.us/journal/index.php/ijssh
Vol. 3 No. 3, December 2019, pages: 1 9
e-ISSN: 2550-7001, p-ISSN: 2550-701X
https://doi.org/10.29332/ijssh.v3n3.338

\title{
Brain Quadrant Model Learning Styles
}

\author{
CrossMark
tcick for updates \\ Olga Viviana Torres Teran ${ }^{a}$, Maria Antonia Velez Tuarez b, María Pamela Zambrano Quiroz c, \\ Maria Elena Moya Martinez ${ }^{\mathrm{d}}$
}

Article history: Received 09 April 2019, Accepted: 31 August 2019, Published: 20 September 2019

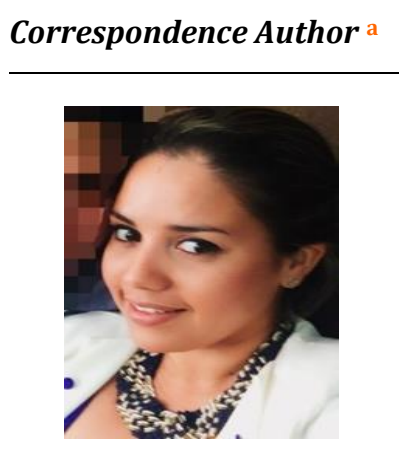

Keywords

brain;

learning strategy;

learning toy;

quadrants;

teaching;

\begin{abstract}
This work was carried out with the interest of identifying learning styles based on the brain quadrant model to improve teaching. Current pedagogical orientations show a growing interest in teaching strategies, which circumvent traditional models, benefiting learning effectively and innovatively. The brain quadrant model helps guide people's personal and professional roles based on existing Sperry models (left and right hemisphere) and the McLean model (cortical and limbic brain). Herrmann crossed these two models to find the source of personal creativity based on the dominance of one or the other quadrant in each person so that they can recognize what would be the effective way to improve teaching. Through explanatory inquiry, cognitive innovation developed in teaching and honing cognitive, affective-social psychomotor skills to achieve different styles of learning and applicability is evaluated in content in daily life.
\end{abstract}

e-ISSN: 2550-7001, p-ISSN: 2550-701X ๑ Copyright 2019. The Author. SS Journals Published by Universidad Técnica de Manabí. This is an open-access article under the CC BY-SA 4.0 license (https://creativecommons.org/licenses/by-sa/4.0/) All rights reserved.

\section{Contents}

Abstract

1. Introduction.

2. Materials and Methods...

3. Results and Discussions

3.1 Brain Quadrant Model

3.2 Left Cortical (Rational)

3.3 Left Limb (organized)

3.4 Cortical Right (Experimental)

3.5 Right (Sentimental)

a Pontificia Universidad Católica del Ecuador, Portoviejo, Ecuador

b Pontificia Universidad Católica del Ecuador, Portoviejo, Ecuador

c Pontificia Universidad Católica del Ecuador, Portoviejo, Ecuador

d Pontificia Universidad Católica del Ecuador, Portoviejo, Ecuador 


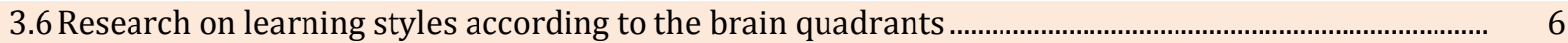

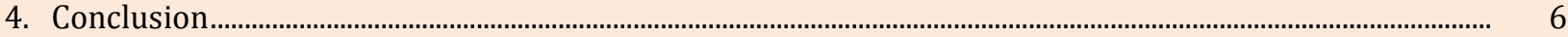

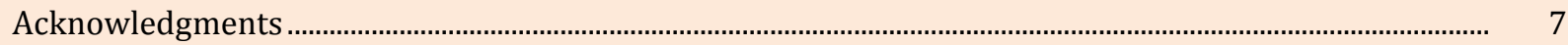

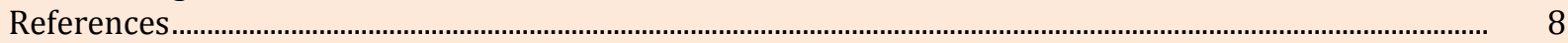

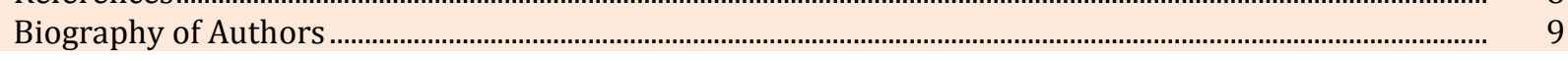

\section{Introduction}

Reasoning in the human brain is a continuous legacy of several publications not fully explained. The levels of application of the apprehended and the use of the educated, posed by The Piagetian science, transforms the supposed guidelines taken and resolved with valuable levels of experiential, vocational, social and interaction Cognitive.

From the beginning of how it assimilates the human psyche to the divergence of others on Earth. It innovates the path of a practitioner who combines his cognitive, emotional-emotional and spiritual learning, how the necessary mediation is allowed from education, with an opinion and qualifying profile (Flórez et al., 2015).

The current educational model aims to devise better learning, during the teaching process, from a new vision, schools should orient teaching-learning efforts towards dynamic processes that meet the needs of companies that are continuously transformed (Arellano et al., 2017; Mendoza et al., 2019; Vasquez et al., 2019).

The student's learning styles are due to endogenous and exogenous elements of the biological or sociocultural nature, such as sex, age and educational practices, the role of parents in their formation, socioeconomic status and various factors that afflict career and personal perspectives such as academic benefit, study skills, professional and occupational decision-making, self-esteem (Gravini, 2006).

The objective of this present work is to identify the learning styles in the brain quadrant model for better teaching, through the purpose of the explanatory inquiry.

\section{Materials and Methods}

For the research, the methodology of explanatory inquiry was used, in which the content and cognitive innovation developed in the teaching and improvement of cognitive, affective-social psychomotor skills are evaluated, based on the analysis of content in the review of different bibliographic sources. In which the benefits of this style of teaching were identified.

\section{Results and Discussions}

The learning style is part of the undeniable fact that they are different people, and this divergence is reflected in traits such as age, the level of knowledge and theme interests that has become a complex field of study (Rojas et al., 2006; Chávez et al., 2019; Suarez et al., 2019).

In the basic and health sciences, important efforts have arisen to conceptualize the characteristics of learning in students. These initiatives have sought ways to create educational environments that promote effective learning. In recent decades some research Correa (2006), has shown that people have different ways of learning and set different strategies, known as cognitive styles. A term first used, in the 1950s by cognitivist psychologists.

The first studies were based on the expression of particular ways of perceiving and processing the information of individuals. These cognitive styles are defined as the individual variation of ways to perceive, remember, and think, or as different ways to learn, store, transform, and use information. For their part, Learning Styles are considered as a set of strategies that subjects use on a regular basis to meet learning objectives. These strategies cover not only cognitive strategies but also involve motivational, personality and affective and physiological traits that serve as relatively stable indicators (Martínez et al., 2013).

Cognitive traits have to do with the way students structure content, how they use concepts, interpret information, solve problems, and select the appropriate means of representation whether: visual, auditory or 
kinesthetic. For its part, affective traits are more linked to the motivations and expectations that influence learning, while physiological traits are related to the biotype and biorhythm of the student (Alonso et al., 2002). In short, styles refer to various ways of capturing information and addressing task solution.

It is clear that any style can be related to aspects of personality, environment, education, among others. In addition, both educational and family forms, and the interaction between the cognitive style of the student and the teacher have significant repercussions on the way of learning. The theory of learning styles seems to confirm that some differences detected among students are due to their personal style of learning, and linked to it is the current pedagogical intervention, which is aimed at putting the student in the provision of learn to learn (Martínez et al., 2013; Alava \& Martinez, 2019; Reina, 2019).

\subsection{Brain Quadrant Model}

The Brain Quadrant model by Ned Herrmann, a German psychoanalyst researcher, makes an analogy of the brain with a globe: with four cardinal points, representing four different ways of operating, thinking, believing and learning (Rojas et al., 2006; Tuarez et al., 2019).

The author Hénard (2010), developed the model that has had a profound impact on an educational level, is based on David McLean's Triune brain theory. Figure 1 shows the brain regions raised.

\begin{tabular}{l} 
Reptilano \\
•It has survival and reproduction functions. Responsible for aggressive behaviors in \\
humans. \\
\hline Limbico \\
• Responsible for deep emotions, where love, hate, fear and pleasure. \\
\hline Neo-cortex \\
•The largest part of the brain, where laws, morals, ethics, rules, and behavior \\
patterns are found through higher cognitive processes.
\end{tabular}

Figure 1. Brain regions

Source: (Hénard 2010)

The brain can be divided into two halves, Sperry model, called hemispheres: left, responsible for logical processes, language, mathematical processes, order, and structure. Right is creative, artistic, both are related. Each activity is involved in a part of the hemispheres. From this mixture of three regions and two hemispheres, Herrmann draws his interpretive model of how reality is perceived in terms of dominance. Its model is inspired by the knowledge of brain functioning, where one of these quadrants has its own characteristics (Celis et al., 2014).

Scientist Herrmann developed a model that draws inspiration from the knowledge of brain functioning, he describes as a metaphor the different ways of living with the world (Rojas et al., 2006).

Herrmann describes the preferences of thought by partnering them in some quadrant of the brain that allows knowing about the ways of thinking of students, this helps to have good results, in stimulating aspects of the higher psychological functions, by the neuropsychology includes the functions of attention, language, reading and writing, praxis, gnosis, memory, thought, executive functions and the state of wakefulness (Aregón \& Jiménez, 2009).

The quadrants represent the different ways the subject has to operate, think, learn and live with the world around them, these explain that the model proposed by Herrmann within educational field helps to recognize relevant characteristics of the (Velasquez et al., 2007).

Teran, O. V. T., Tuarez, M. A. V., Quiroz, M. P. Z., \& Martinez, M. E. M. (2019). Brain quadrant model learning styles. International Journal of Social Sciences and Humanities, 3(3), 1-9. https://doi.org/10.29332/ijssh.v3n3.338 


\subsection{Left Cortical (Rational)}

This part of the brain has difficulty integrating knowledge from informal experiences, prefers to know the theory, how things work before moving on to experimentation. Likes solid, argued classes, supported by facts and evidence, the student goes to class to learn, take notes, advance the program to strengthen knowledge at the end of the course (Celis et al., 2014), as shown in Figure 2.

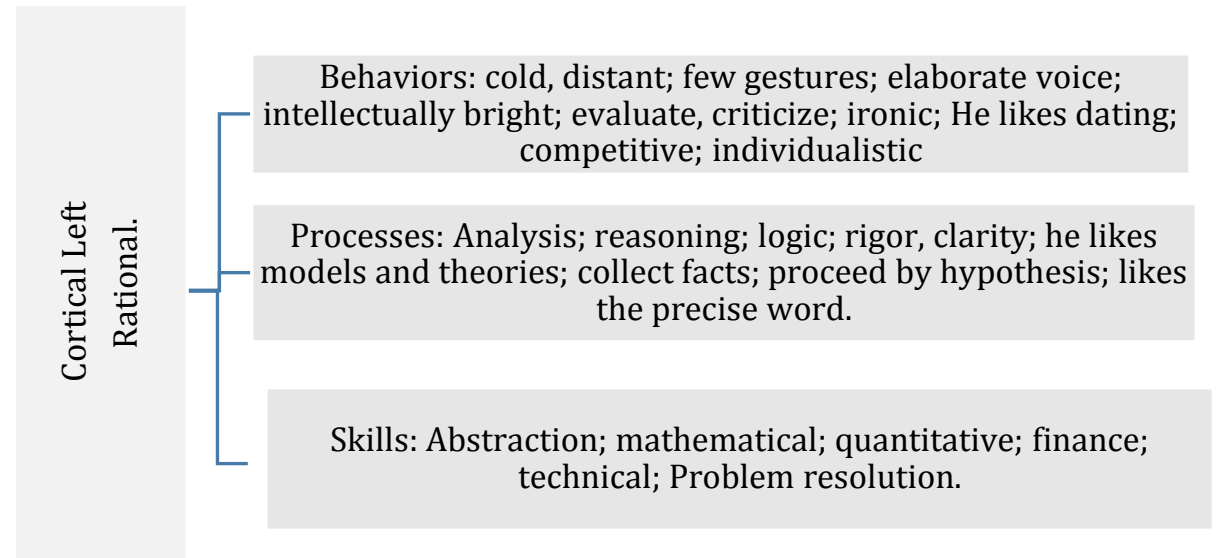

Figure 2. Rational left cortical Source: (Celis et al., 2014)

\subsection{Left Limb (organized)}

The left limb attaches to the organization, likes planned advances, needs a structured class to integrate knowledge and have the encouragement available to them (Celis et al., 2014), as shown in Figure 3.

\begin{tabular}{|c|c|}
\hline Behavior & $\begin{array}{l}\text {-ntrovert; emotional, controlled; thorough, maniacal; monologue; } \\
\text { He likes formulas; conservative, faithful; Defend your territory, } \\
\text { love power. }\end{array}$ \\
\hline Processes & $\begin{array}{l}\text {-Plan; formalize; structure; define the procedures; ritualistic; } \\
\text { methodical. }\end{array}$ \\
\hline Competitions & $\begin{array}{l}\text {-Administration; organization; realization, commissioning; male } \\
\text { driver; speaker; consecrated worker. Methodical, organized, and } \\
\text { often meticulous. He likes the class to develop according to a } \\
\text { known and routine liturgy }\end{array}$ \\
\hline
\end{tabular}

Figure 3. Left limb. (organized)

Source: (Celis et al., 2014)

This part needs openness and long-term vision of the future appreciates the originality, novelty, and concepts that make you think. He takes few notes because he knows how to select the essentials, sometimes he impresses as a dreamer or disconnected, but another surprise with unexpected observations and original projects (Celis et al., 2014), as seen in Figure 4. 
Cortical Law (experimental)

\section{Behaviors}

Original humor; taste for risk; space; simultaneous; He likes discussions; futuristic; jump from one subject to another; bright speech; Independent.

\section{Processes}

Conceptualization; synthesis; globalization; imagination; intuition; display; acts by associations; Integrates through images and metaphors.
Competition

Creation; innovation; entrepreneurship; artist; investigation; future vision.

Figure 4. Cortical right. (experimental)

Source: (Celis et al., 2014)

\subsection{Right (Sentimental)}

In this case people are limited to communication and relationship. It works by feeling and instinct, you need to share what you hear to verify that you have understood the lesson (Celis et al., 2014), as seen in Figure 5.

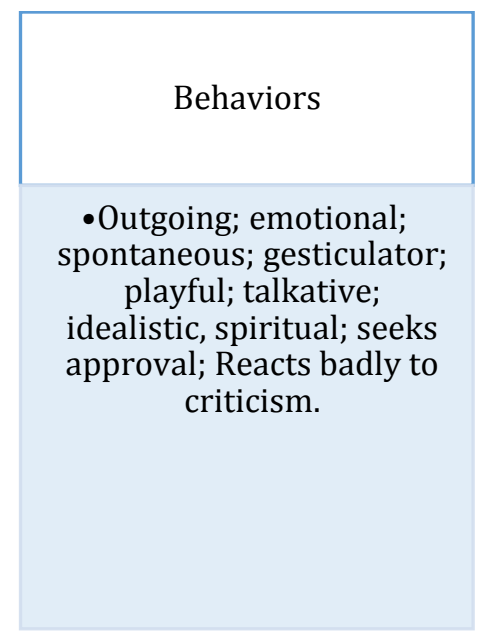

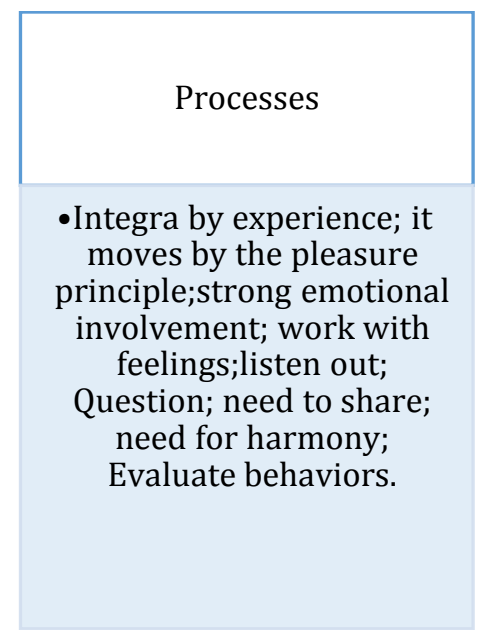

Figure 5. Right limb (sentimental) Source: (Celis \& et al., 2014)

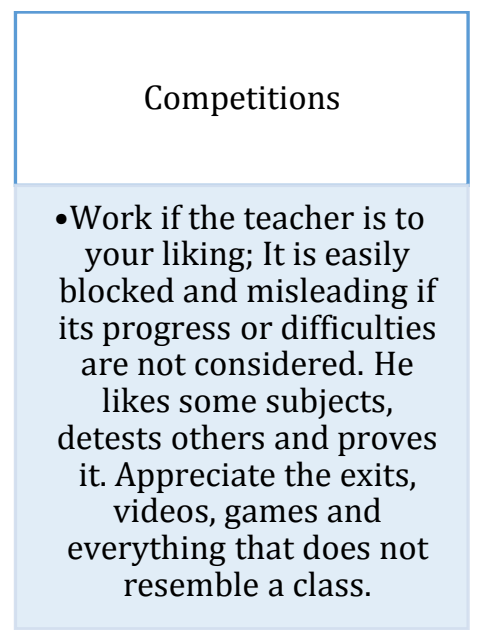

The development of the cerebral cortex stimulates one of the four quadrants predominantly, generating that individuals tend to have particular tastes, preferences, mental processing and personality outlining (Alcalá et al., 2013).

And this results in expressions being activated in complex simple methods, since creativity is not located in a specific place of the cerebral cortex (Ramírez, 2015), gaining learning from creativity.

\subsection{Research on learning styles according to the brain quadrants}

Table 1 shows the reflections made by the following authors who have worked on the learning styles according to the brain quadrant model.

Teran, O. V. T., Tuarez, M. A. V., Quiroz, M. P. Z., \& Martinez, M. E. M. (2019). Brain quadrant model learning styles. International Journal of Social Sciences and Humanities, 3(3), 1-9. https://doi.org/10.29332/ijssh.v3n3.338 
Table 1

Analysis of authors' approaches

\begin{tabular}{lll}
\hline Author & Year & Reflection \\
\hline Gravini & 2006 & $\begin{array}{l}\text { It proposes that students' learning styles follow internal and } \\
\text { external elements of biological order. }\end{array}$ \\
Martinez \& et al & 2013 & $\begin{array}{l}\text { He mentions that they're not just cognitive strategies. They } \\
\text { also involve motivational, personality and cognitive, } \\
\text { affective and physiological traits that serve as relatively } \\
\text { stable indicators. }\end{array}$ \\
& 2010 & $\begin{array}{l}\text { It states that the brain was divided into three regions. } \\
\text { I propose that the brain can be divided into two halves; the } \\
\text { Henard } \\
\text { Celis \& et al }\end{array}$ \\
Aregón \& Jiménez & 2014 & $\begin{array}{l}\text { Sperry model, called hemispheres. } \\
\text { They considered that their model inspired by the } \\
\text { knowledge of brain functioning, where each of these } \\
\text { quadrants has its own characteristics. }\end{array}$ \\
\hline
\end{tabular}

The current educational model, proposes to devise a better teaching during the instruction process, from a new vision, schools should orient their teaching-learning efforts towards more dynamic processes, which meet the needs of societies that are continually transformed.

While the styles of the students, they follow endogenous and exogenous elements of biological or sociocultural order, such as sex, age and educational practices, the role of parents in their formation, socioeconomic status and various factors that afflict career and personal perspectives such as academic benefit, study skills, professional and occupational decision-making, self-esteem (Gravini, 2006).

The first studies are based on the expression of particular ways of perceiving and processing the information of individuals. These cognitive styles are defined as the individual variation of ways to perceive, remember, and think, or as different ways to learn, store, transform, and use information. For their part, learning styles are considered as a set of strategies that subjects use on a regular basis to meet the objectives of learning. These strategies cover not only cognitive strategies, but also involve motivational, personality and cognitive, affective and physiological traits that serve as relatively stable indicators (Martínez et al., 2013).

The philosopher Hénard (2010), developed the model that has had a profound impact on an educational level, and is based from David McLean's triune brain theory which established that the brain was divided into three regions, while (Celis et al., 2014), I propose that the brain can be divided into two halves; the Sperry model, called hemispheres; one left, in charge of logic, language, mathematics, order and structure, and the right is the creative - artistic both are related.

In all the activities carried out a part of each hemisphere is involved, of this composition of three regions and two hemispheres Herrmann draws its interpretative model from how the situation in techniques of dominance is observed. While (Aregón \& Jiménez, 2009), they considered that their model is inspired by knowledge of brain activity, where each of the quadrants has differences of its own. It also describes the preferences of thinking by partnering them in a quadrant of the brain allowing to know about the ways of analyzing and thinking students, this helps to have good results, in stimulating aspects of psychological functions neuropsychology's functions include attention, language, reading and writing, praxis, gnosis, memory, thinking, executive functions and wakefulness

\section{Conclusion}

Learning styles are content that changes the way you educate yourself or learn and teach. It is inevitable to take them into account when executing, planning and evaluating the contents, for teachers and students, it is necessary to modernize them, thus optimizing the chances of success of their students, in the process of teaching-learning.

In conclusion, the student must be instructed in an inherent, inclusive and efficient way. Creativity, knowledge, teaching, decision-making and problem solving need the established action of the brain and so the 
brain quadrant model was based on the reason that benefits to guide the own and professional roles of individuals to effectively achieve excellent teaching.

It is inescapable to provide instructions on learning styles, as well as to train the student taking into account all the particularities will manage to reason, through experience.

\section{Acknowledgements}

The author would like to thank the IJSSH editorial committee team for their valuable time, support and advice to complete this study.

Teran, O. V. T., Tuarez, M. A. V., Quiroz, M. P. Z., \& Martinez, M. E. M. (2019). Brain quadrant model learning styles. International Journal of Social Sciences and Humanities, 3(3), 1-9. https://doi.org/10.29332/ijssh.v3n3.338 


\section{References}

Alava, E. E., \& Martinez, M. E. M. (2019). Impact of teaching-learning process for brain. International Journal of Health Sciences, 3(1), 33-40. https://doi.org/10.29332/ijhs.v3n1.304

Alcalá, F. (2013). Diferenciación vertical y sofisticación exportadora en el comercio internacional. Fundacion BBVA.

Alonso, F., Beletskaya, I. P., \& Yus, M. (2002). Metal-mediated reductive hydrodehalogenation of organic halides. Chemical reviews, 102(11), 4009-4092.

Aragón-Vargas, LF, Moncada-Jiménez, J., Hernández-Elizondo, J., Barrenechea, A., \& Monge-Alvarado, M. (2009). Evaluation of pre-game hydration status, heat stress, and fluid balance during professional soccer competition in the heat. European Journal of Sport Science , 9 (5), 269-276.

Arellano, M., \& Bonhomme, S. (2017). Quantile selection models with an application to understanding changes in wage inequality. Econometrica, 85(1), 1-28. https://doi.org/10.3982/ECTA14030

Celis, M. (2014). Learning styles according to brain quadrant theoria in students of the university center uaem valley chalco. Cinvestav-IPN, 139-148.

Chávez, E. J. M., Pibaque, W. L. D., Chávez, W. J. M., \& López, M. M. L. (2019). Learning problems on brain disorders. International Research Journal of Engineering, IT \& Scientific Research, 5(5), 8-15. https://doi.org/10.21744/irjeis.v5n5.723

Correia, A. M. R., Paulos, A., \& Mesquita, A. (2009). Virtual communities of practice: Investigating motivations and constraints in the processes of knowledge creation and transfer. Electronic Journal of Knowledge Management, 8, 11-20.

Flórez, R., Castro, J., Gómez, D., Galvis, D., \& Arias, N. (2015). Studies on the processes of learning and their mediations in the schoolchildren of the capital district. Bogotá D.C.: Universidad Nacional de Colombia repository headquarters bogotá. Obtained from http://biblioteca.idep.co/multimedia/10000562.pdf

Gravini, ML Other (2006). Learning styles a research proposal. Psychogent Magazine , 35-41.

Hénard, F. (2010). Let's learn the lesson. A review of the quality of teaching in higher education. Educational profiles , 32 (129), 164-173.

Martinez, G. (2013). Application of Herrmann's cerebral quadrant model and its relationship to learning styles. University of the Mexico Center UCEM.

Mendoza, L. R. M., Martinez, M. E. M., \& Suarez, A. M. S. (2019). The brain as a fundamental axis in learning process. International Research Journal of Engineering, IT \& Scientific Research, 5(4), 38-45. https://doi.org/10.21744/irjeis.v5n4.689

Ramírez-Ruiz, B., Junqué, C., Martí, M. J., Valldeoriola, F., \& Tolosa, E. (2006). Neuropsychological deficits in Parkinson's disease patients with visual hallucinations. Movement disorders: official journal of the Movement Disorder Society, 21(9), 1483-1487.

Reina, A. L. V. (2019). The brain and learning on initial students. International Journal of Health Sciences, 3(2), 38-43. https://doi.org/10.29332/ijhs.v3n2.329

Rojas, G. (2006). Learning styles and thought styles among unicist students. Pedagogic studies, pp,49-75.

Suarez, A. M. S., Martinez, M. E. M., \& Mendoza, L. R. M. (2019). Brain and learning. International Journal of Social Sciences and Humanities, 3(2), 128-135. https://doi.org/10.29332/ijssh.v3n2.302

Tuarez, M. A. V., Delgado, R. I. Z., Teran, O. V. T., \& Martine, M. E. M. (2019). The brain and its role on learning process. International Journal of Physical Sciences and Engineering, 3(2), 27-33. https://doi.org/10.29332/ijpse.v3n2.326

Vasquez, B. S. G., Martinez, C. J. B., Martinez, M. E. M., \& Vasquez, M. A. I. (2019). Brain and learning on adolescence stage. International Research Journal of Engineering, IT \& Scientific Research, 5(5), 1-7. https://doi.org/10.21744/irjeis.v5n5.720

Velasquez, B., Remolina, C., \& Calle, M. (2007). Determination of the brain dominance profile or thought forms of first semester students of the bacteriology program and clinical laboratory of the College of Cundinamarca. Nova-Scientific Publication, 48-56. 


\section{Biography of Authors}

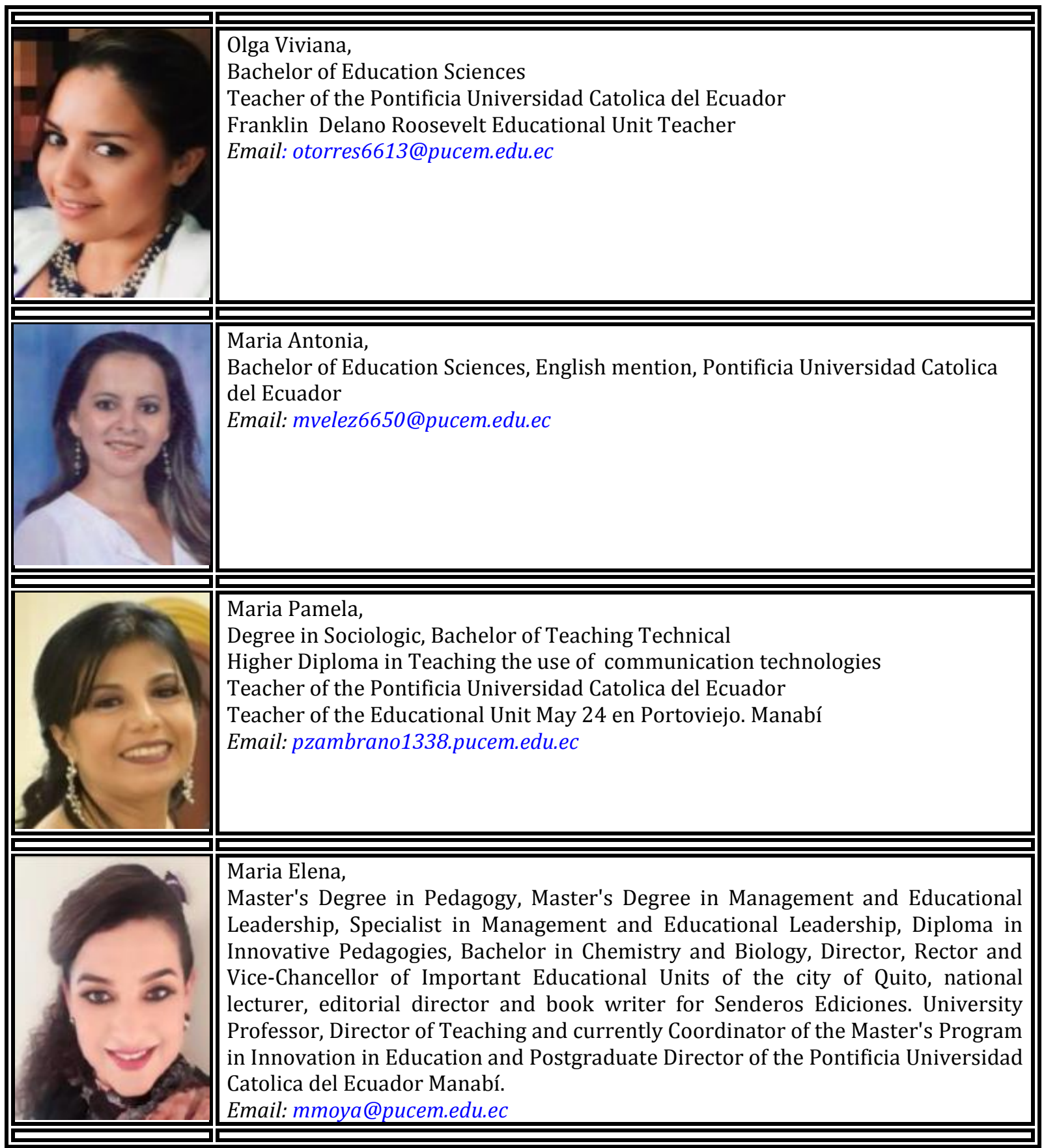

Teran, O. V. T., Tuarez, M. A. V., Quiroz, M. P. Z., \& Martinez, M. E. M. (2019). Brain quadrant model learning styles. International Journal of Social Sciences and Humanities, 3(3), 1-9. https://doi.org/10.29332/ijssh.v3n3.338 